\title{
Serum surfactant protein $D$, lung function decline, and incident chronic obstructive pulmonary disease: a longitudinal study in Beijing
}

\author{
Ji-Ping Liao', Xi Wang ${ }^{1}$, Feng Liu ${ }^{2}$, Yuan Cheng ${ }^{1}$, Zhan-Wei Hu ${ }^{1}$, Li-Na Zhang ${ }^{3}$, Guo-Guang Xia ${ }^{4}$, \\ Cheng Zhang ${ }^{1}$, Jing $\mathrm{Ma}^{1}$, Guang-Fa Wang ${ }^{1}$
}

${ }^{1}$ Department of Respiratory and Critical Care Medicine, Peking University First Hospital, Beijing, China; ${ }^{2}$ Second Outpatient Department of Aviation General Hospital, Beijing, China; ${ }^{3}$ Department of Internal Medicine, Shichahai Community Health Care Center, Beijing, China; ${ }^{4}$ Department of Respiratory and Critical Care Medicine, Beijing Jishuitan Hospital, Beijing, China

Contributions: (I) Conception and design: JP Liao, GF Wang; (II) Administrative support: GF Wang; (III) Provision of study materials or patients: None; (IV) Collection and assembly of data: X Wang, F Liu, Y Cheng, ZW Hu, LN Zhang, GG Xia, C Zhang, J Ma; (V) Data analysis and interpretation: JP Liao, GF Wang; (VI) Manuscript writing: All authors; (VII) Final approval of manuscript: All authors.

Correspondence to: Guang-Fa Wang. Department of Respiratory and Critical Care Medicine, Peking University First Hospital, No. 8 Xishiku Street, Beijing 100034, China. Email: wangguangfa@hotmail.com.

Background: Chronic obstructive pulmonary disease (COPD) has become a major public-health problem in China. Surfactant protein D (SP-D) is a very promising biomarker and therapeutic target for COPD. To assess whether baseline serum SP-D is associated with lung function decline and incident COPD.

Methods: This longitudinal study was initiated in 2009 in a community in Beijing. Data were collected on spirometry, and the baseline level of serum SP-D was measured in 772 non-COPD subjects aged 40-70 years old. In 2012, spirometry was repeated in 364 individuals, 37 of whom subjects had incident COPD.

Results: From 2009 to 2012, subjects with incident COPD had a more rapid decline in FEV1 (MD 98.27 vs. MD $43.41 \mathrm{~mL}$ ) compared with those without COPD. There was no association between baseline serum SP-D and the COPD incidence. Smoking ( $\mathrm{OR}=2.72 ; \mathrm{P}=0.002)$ and age $(\mathrm{OR}=1.06 ; \mathrm{P}=0.000)$ were risk factors for COPD. The rate of FEV1 decline varies widely in the general population, and the univariate analysis showed that baseline serum SP-D levels ( $\mathrm{R}=-0.169 ; \mathrm{P}=0.003)$, income level, home-road distance, and statin use were inversely correlated with the decline in FEV1. After multivariable analyses, only smoking was consistently associated with the decline in FEV1.

Conclusions: There was no correlation between baseline serum SP-D levels and incident COPD in a general population. Smoking and age were major risk factors for COPD. The effect of serum SP-D levels on the decline in FEV1 needs further investigation.

Keywords: Surfactant protein D (SP-D); chronic obstructive pulmonary disease (COPD); FEV1; decline in lung function; longitudinal study

Submitted Apr 15, 2020. Accepted for publication Nov 02, 2020.

doi: $10.21037 /$ jtd-20-1675

View this article at: http://dx.doi.org/10.21037/jtd-20-1675

\section{Introduction}

Chronic obstructive pulmonary disease (COPD) is associated with significant economic burden worldwide. It was the fourth leading cause of death worldwide in 2010, and it is predicted to be the third by 2020 (1). In China, the prevalence has ranged from $8.2 \%$ to $13.6 \%$ among adults aged 40 years or older $(2,3)$. The pathobiology of COPD is characterized by impaired lung growth, accelerated decline in lung function, lung and systemic inflammation and lung injury (GOLD 2019). Establishing a causal link between the 


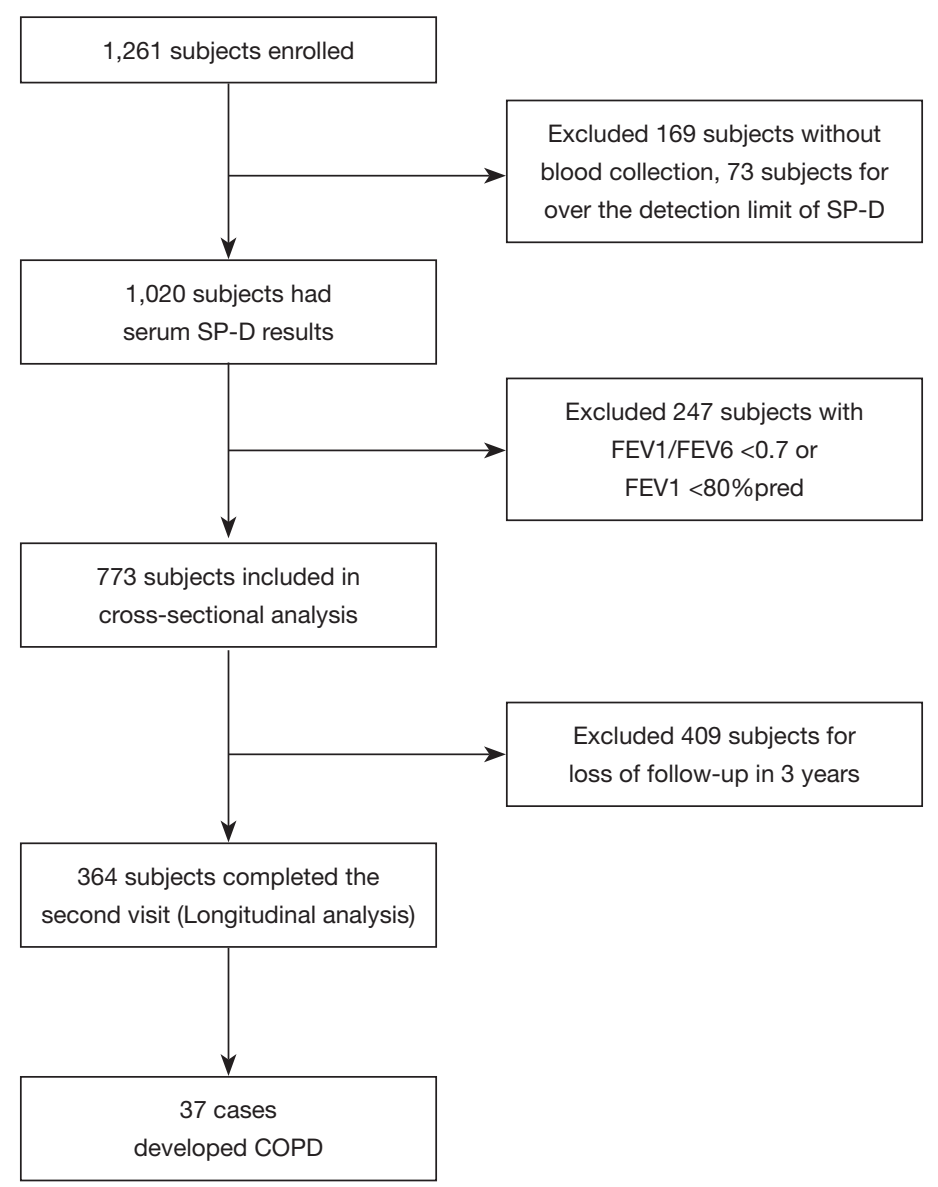

Figure 1 Flow chart of participant selection.

levels of selected proteins and the development of COPD is a promising step toward their development as both biomarkers and treatment targets.

Surfactant protein D (SP-D) is synthesized in the endoplasmic reticulum of lung type II epithelial cells and is secreted into the extracellular space by exocytosis (4). SP-D can be reliably assayed in blood, bronchoalveolar lavage (BAL) fluid and lung tissue, and it is a very promising biomarker and therapeutic target for COPD (5). Some clinical studies in COPD patients have shown that the level of SP-D is elevated in those with a diagnosis of COPD and is inversely associated with lung function $(6,7)$. The level of SP-D correlates well with disease severity and exacerbation and is responsive to steroid treatment (6).

However, most of the risk factors for COPD in China come from cross-sectional studies, which identify associations rather than causal relationships $(2,8,9)$. In this study, we used data from a 3-year longitudinal communitybased cohort study in a general population without COPD in Beijing, to determine whether the baseline serum SP-D level is associated with a rapid decline in FEV1 and incident COPD.

\section{Methods}

\section{Study design}

The study cohort was sourced from a previous epidemiological study of COPD in 2009, as previously reported (10). In 2009, 1,270 subjects aged 40-75 years were recruited from the Shichahai community in Beijing. In total, 1,261 participants completed the questionnaires and spirometry tests. Serum SP-D level detection was completed in 1,020 subjects, and 773 subjects with normal lung function were included in the cross-sectional analysis. In 2012, 364 subjects completed the second visit and were included in the final analysis (Figure 1). This study was conducted in accordance with the amended Declaration of 
Helsinki. The Ethics Committee of Peking University First Hospital approved the protocol (approval number 2009168 ), and written informed consent was obtained from all subjects.

\section{Data collection}

Demographic data, medical and medication histories, St. George's Respiratory Questionnaire (SGRQ) data, income level, education level, smoking history, occupational exposure, and family history were collected. There are six major roads across the Shichahai community. Home-road distance was defined as the distance from the home address to the nearest major road, measured using AMAP 2.0 (AutoNavi Software Co., Ltd., Beijing, China). We divided the distance into three categories: $1,<100 \mathrm{~m} ; 2,100-200 \mathrm{~m}$; and $3,>200 \mathrm{~m}$, as previously reported (10).

\section{SP-D measurement}

Blood samples were collected and centrifuged $(3,000 \mathrm{r} / \mathrm{min}$, $\mathrm{r}=15 \mathrm{~cm}, 10 \mathrm{~min})$. Serum samples were stored at $-80^{\circ} \mathrm{C}$. SP-D levels were tested by enzyme-linked immunosorbent assay (ELISA) (Hycult Biotech, HK335). Blood collection from participants with acute respiratory infections was postponed until 2 weeks after recovery.

\section{Lung function}

FEV1 and FEV6 were measured using the portable spirometer COPD 6 (Vitalograph Ltd., County Clare, Ireland), as previously reported (10). When the FEV1/ FEV6 ratio was $<0.7$, a bronchodilator test was performed. COPD was diagnosed when the FEV1/FEV6 was $<0.7$ after the bronchodilator test (11).

Changes in pre-bronchodilator FEV1 were based on the slope defined by the first and last data points. Annualized FEV1 was classified into three categories based on an extreme definition of rapid decline (annualized absolute loss of FEV1 $>40,20-40$, and $<20 \mathrm{~mL} / \mathrm{y}$ ), as previously reported (12).

\section{Data analysis}

IBM SPSS Statistics for Windows, Version 21.0 (IBM Corp., Armonk, USA) was used for the statistical analyses. Summary statistics, including the mean \pm standard deviation (SD), median (interquartile range, IQR), and number of cases (percentage) for categorical variables, were obtained.
Initially, for the 2009 datasets, we compared the differences in serum SP-D levels based on smoking habits. We analysed the cross-sectional association between serum SP-D levels and FEV1 in a multiple linear regression with adjustment for the a priori confounding factors of age, sex, height, smoking status, and cigarette pack-years smoked. Potential confounding factors, including body mass index (BMI), statin use, and respiratory symptoms, were investigated by univariate analysis for their effect on the association between SP-D and FEV1, and if a potential confounding effect was identified, it was added to the a priori model.

The longitudinal analysis used both the 2009 and 2012 datasets. The primary outcome was the incidence of COPD, and the secondary outcome was the rate of the decline in FEV1. Baseline data and the decline in FEV1 were compared between the subjects with incident COPD (COPD group) and those without (non-COPD group) with $\mathrm{T}$ tests, Kruskal-Wallis $\mathrm{H}$ tests or chi-square tests. Binary logistic regression analysis was used to assess the incidence of COPD. Univariate analysis was adopted for correlation analyses between the rate of decline in FEV1, baseline serum SP-D level and other potential confounding factors. If a potential association was identified, the variable was added to the multivariate linear regression to assess the association between serum SP-D levels and the decline in FEV1. $\mathrm{P}<0.05$ was considered statistically significant.

\section{Results}

From the total cohort of 772 eligible non-COPD subjects, 364 completed the second visit, 37 of whom had developed COPD after 3 years. The median baseline serum level of SP-D was $44.1 \mathrm{ng} / \mathrm{mL}$ (IQR, 34.4-70.6). There were no differences in serum SP-D level, sex, BMI, FEV1/Pred\%, or smoking status between subjects who were followed up and those who were lost to follow-up. Compared with the subjects who were followed up, the subjects lost to followup were younger $(56.9 \pm 9.2$ and $58.3 \pm 8.6$ y, respectively, $\mathrm{P}=0.027)$ and had higher FEV1/FEV6 ratios $(0.83 \pm 0.06$ and $0.84 \pm 0.07$, respectively, $\mathrm{P}=0.015$ ) at baseline.

\section{Cross-sectional analysis of SP-D and lung function}

The baseline characteristics of the cross-sectional population in 2009 are shown in Table 1. Current and ex-smokers had a higher proportion of males than nonsmokers. Current smokers had a lower FEV1, FEV1/FEV6 ratio and FEV6 
Table 1 Baseline characteristic of cross-sectional population 2009

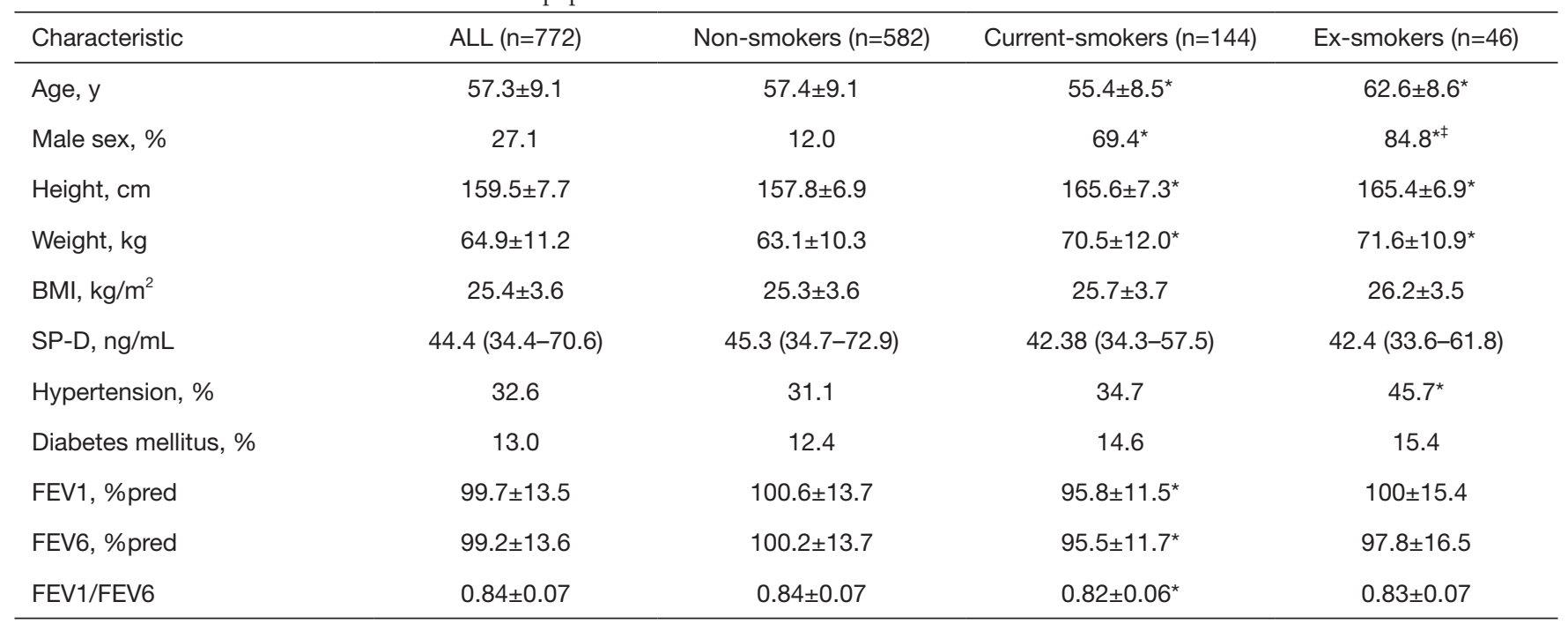

Data are presented as mean $\pm \mathrm{SD}$, median (interquartile range) or No. (\%). ${ }^{*}, \mathrm{P}<0.05$ comparing with non-smokers; ${ }^{\ddagger}, \mathrm{P}<0.05$ comparing with current-smokers. BMI, body mass index; SP-D, serum surfactant protein D; FEV1, forced expiratory volume in 1 s; FEV6, forced expiratory volume in $6 \mathrm{~s}$.

than nonsmokers and ex-smokers. There was no association between SP-D and FEV1 after the univariate analysis $(\mathrm{P}=0.82)$ and multivariate linear regression $(\mathrm{P}=0.69)$. No correlations were found between SP-D levels and other parameters, such as age, sex, BMI, smoking status, comorbidities, statin use and respiratory symptoms. In the subgroup analysis, there were no differences in SP-D levels among current smokers, ex-smokers and nonsmokers (Figure 2A).

\section{Longitudinal analysis of SP-D and incident COPD}

There were no differences in the baseline level of SP-D between subjects with incident COPD (MD, $45 \mathrm{ng} / \mathrm{mL}$ ) and those without incident COPD (MD, $40 \mathrm{ng} / \mathrm{mL}$ ) (Table 2 and Figure 2B). Subjects with incident COPD had an older baseline age, more smoking pack-years, and a lower baseline FEV1/FEV6 ratio than those without COPD (Table 2). No significant differences were observed in income level, education level, chronic cough, home road distance, comorbidities, statin use, and lower respiratory tract infections in childhood between the two groups.

FEV1 decline in subjects with incident COPD was approximately two-fold greater than that in subjects without COPD (Table 3). The multivariate analysis revealed no effect of baseline serum SP-D on incident COPD (Table 4). Age (OR $=1.06$ per one-year increase; $95 \%$ CI, 1.02-1.1; $\mathrm{P}=0.000$ ) and smoking status $(\mathrm{OR}=2.72 ; 95 \% \mathrm{CI}, 1.24-5.94 ; \mathrm{P}=0.002)$ were significant predictors of incident COPD among middleand old-aged subjects without COPD (Table 4).

\section{Longitudinal analysis of SP-D and decline in FEV1}

Univariate analysis showed that baseline serum SP-D levels ( $\mathrm{R}=-0.169, \mathrm{P}=0.003)$, income level $(\mathrm{R}=-0.168, \mathrm{P}=0.001)$, home-road distance $(\mathrm{R}=-0.294, \mathrm{P}=0.00)$, and statin use $(\mathrm{R}=-0.168, \mathrm{P}=0.001)$ were inversely correlated with the decline in FEV1. Baseline serum SP-D levels were higher in subjects with an annualized absolute loss of FEV1 $<20 \mathrm{~mL} / \mathrm{y}$ than in those with a more rapid decline in FEV1 (Figure 2C). After multivariable analyses, only smoking was consistently associated with an accelerated decline in lung function, and the rate of decline in FEV1 in smokers was $32.6 \mathrm{~mL} / \mathrm{y}(95 \% \mathrm{CI}, 1.5-63.8 ; \mathrm{P}=0.04)$ greater than that in nonsmokers.

\section{Discussion}

This prospective cohort study presents three major findings. First, we failed to identify a predictive value of baseline SP-D level for incident COPD among middleand old-aged subjects without prevalent lung disease. Aging and smoking were observed to be risk factors for COPD. Second, the accelerated decline in FEV1 was the core feature of the development of COPD. Smoking was the 
A Baseline SP-D levels in subjects divided by smoking status

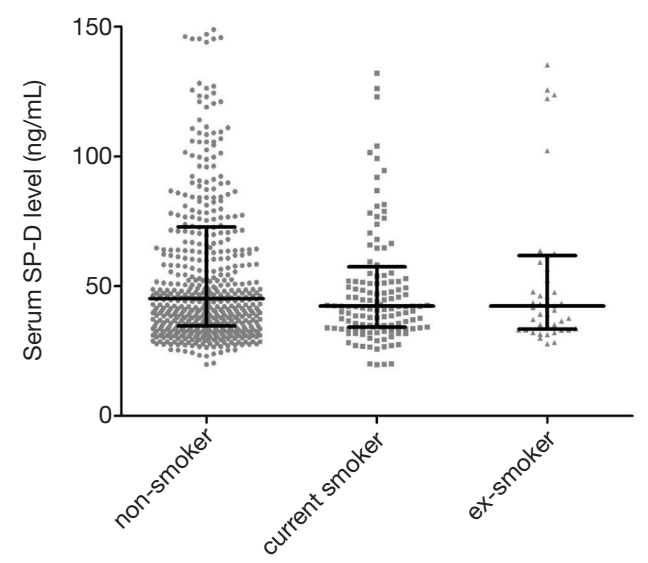

C

Baseline SP-D levels in subjects divided by rate of FEV1 decline
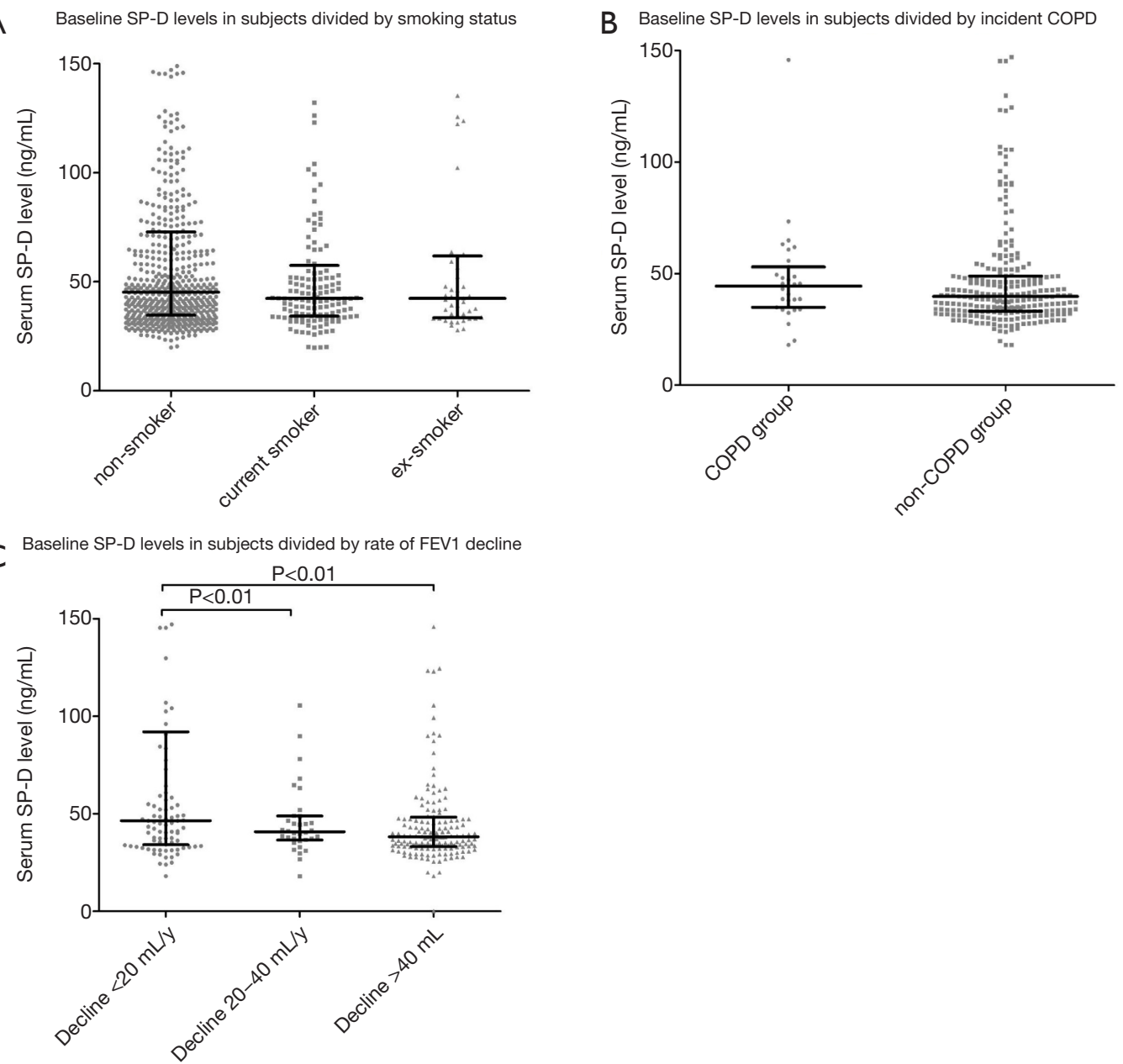

Figure 2 Baseline serum SP-D levels in subjects based on smoking status, incident COPD and rate of FEV1 decline. (A) Baseline serum SP-D level of cross-sectional population $2009(\mathrm{n}=772)$, there were no differences between non-smokers, current smokers and ex-smokers. (B) Baseline serum SP-D level of Longitudinal population from 2009-2012 (n=364), there were no differences between subjects with or without incident COPD. (C) Baseline serum SP-D level in higher in subjects with FEV1 decline $<20 \mathrm{~mL} / \mathrm{y}$ than those with more rapid decline in FEV1.

leading cause of an accelerated decline in FEV1, and there was a potential protective effect of baseline serum SP-D against a rapid decline in FEV1. Third, lower income and higher traffic air pollution exposure were potential risk factors for an accelerated decline in FEV1, and statin use may play a protective role against the decline in FEV1.

To the best of our knowledge, this is the first study to explore the predictive value of serum SP-D in the occurrence of COPD in a general population with normal lung function. Previous studies suggested that levels of serum SP-D were associated with disease severity, progression, and treatment response of COPD $(6,7,13)$.
Lomas and coworkers evaluated serum SP-D levels and the response of those levels to the anti-inflammatory agent prednisolone in 1,888 COPD individuals, and showed that serum SP-D was significantly elevated in COPD patients compared with current and former smokers without airflow obstruction and nonsmokers. COPD patients with high serum SP-D concentrations showed an increased risk of exacerbation over the following 12 months, and treatment with prednisolone resulted in a decrease in serum SP-D levels (6). Sin and coworkers showed that inhaled fluticasone alone or in combination with salmeterol over 4 weeks significantly reduced serum SP-D levels and improved 
Table 2 The characteristics of subjects with incident COPD and those without

\begin{tabular}{|c|c|c|c|}
\hline Characteristic & All $(n=364)$ & $\operatorname{COPD}^{a}(n=37)$ & Non-COPD $(n=327)$ \\
\hline Age, y & $58.3 \pm 8.7$ & $61.9 \pm 8.8$ & $57.9 \pm 8.6^{\star}$ \\
\hline Male sex, \% & 25.2 & 37.8 & 23.8 \\
\hline Height, cm & $159 \pm 7.8$ & $161 \pm 9.2$ & $159 \pm 7.7$ \\
\hline Current and ex-smoker, \% & 22.5 & 35.1 & 21.1 \\
\hline Smoking, Pack-y & $4.4 \pm 11.7$ & $7.8 \pm 14.9$ & $4.0 \pm 11.3^{*}$ \\
\hline Home-road distance of $<100 \mathrm{~m}, \mathrm{n}(\%)$ & $147 / 320(46.0)$ & $17 / 31(54.0)$ & $130 / 289(44.0)$ \\
\hline Chronic cough, \% & 2.7 & 5.4 & 2.4 \\
\hline Infection in childhood, \% & 9.9 & 8.1 & 10.1 \\
\hline Statin use, \% & 12.8 & 5.4 & 12.2 \\
\hline SP-D, ng/mL & $40(17.0)$ & $45(18.0)$ & $40(17.0)$ \\
\hline FEV1/FEV6 & $0.83 \pm 0.06$ & $0.79 \pm 0.07$ & $0.83 \pm 0.06^{\ddagger}$ \\
\hline FEV1, L & $2.29 \pm 0.5$ & $2.25 \pm 0.57$ & $2.29 \pm 0.54$ \\
\hline FEV1, \%pred & $98.2 \pm 14$ & $95.7 \pm 13$ & $98.5 \pm 14$ \\
\hline \multicolumn{4}{|l|}{3 years later } \\
\hline FEV1/FEV6 & $0.81 \pm 0.08$ & $0.65 \pm 0.05$ & $0.82 \pm 0.06^{\ddagger}$ \\
\hline
\end{tabular}

Data are presented as mean $\pm \mathrm{SD}$, median (Interquartile range) or No. (\%). COPD was defined by postbronchodilator $\mathrm{FEV}_{1} / \mathrm{FEV}_{6}<0.7$ at the second visit. Chronic cough was defined as cough lasting for more than 8 weeks in the past year. Infection in childhood was defined low respiratory tract infection below 12 years old. *, $\mathrm{P}<0.05$ for comparison between COPD and non-COPD group; ${ }^{\ddagger}, \mathrm{P}<0.01$ for comparison between COPD and non-COPD group. COPD, chronic obstructive pulmonary disease; SP-D, serum surfactant protein D; FEV1, forced expiratory volume in $1 \mathrm{~s}$; FEV6, forced expiratory volume in $6 \mathrm{~s}$.

Table 3 Decline in FEV1 of COPD and non-COPD

\begin{tabular}{lccc}
\hline Category of FEV1 decline & ALL $(\mathrm{n}=364)$ & COPD $(\mathrm{n}=37)$ & Non-COPD $(\mathrm{n}=327)$ \\
\hline Decline in FEV1, mL/y & $46.4(107.5)$ & $98.3(118.14)$ & $4.4(6.0)$ \\
Ratio of decline in FEV1, \%/y & $1.9(4.6)$ & & $43.4(98.65)^{\star}$ \\
Category of FEV1 decline rate ${ }^{\ddagger}$ & & 67.6 & $1.7(4.3)^{*}$ \\
$>40 \mathrm{~mL} / \mathrm{y}, \%$ & 53.8 & 10.8 & 51.7 \\
$20-40 \mathrm{~mL} / \mathrm{y}, \%$ & 11.0 & 21.6 & 31.3 \\
$<20 \mathrm{~mL} / \mathrm{y}, \%$ & 35.4 & 37.0
\end{tabular}

Data are presented as mean $\pm \mathrm{SD}$, median (interquartile range) or No. (\%). *, $\mathrm{P}<0.01$ for comparison between COPD and non-COPD group; ${ }^{\ddagger}$, $\mathrm{P}=0.054$ for comparison between COPD and non-COPD group. COPD, chronic obstructive pulmonary disease; FEV1, forced expiratory volume in $1 \mathrm{~s}$. 
Table 4 Binary logistic regression for the predictors for incidence of COPD

\begin{tabular}{lcc}
\hline Predictors for incidence of COPD & OR & $95 \% \mathrm{Cl}$ \\
\hline Category of FEV1 decline & 1.42 & $0.90-2.24$ \\
Baseline serum SP-D & 0.99 & $0.98-1.00$ \\
Age & 1.06 & $1.02-1.10$ \\
Smoking & 2.72 & $1.24-5.94$ \\
Category of Home-Road distance & 0.79 & 0.000 \\
\hline
\end{tabular}

Categories of $\mathrm{FEV}_{1}$ decline were defined by an annualized absolute decline of $>40,20-40$, and $<20 \mathrm{~mL} / \mathrm{y}$, respectively (12). Categories of Home-Road distance were defined by $<100$ (grade 0), 100-200 (grade 1), and >200 m (grade 2), respectively (10). COPD, chronic obstructive pulmonary disease; SP-D, Serum surfactant protein D.

patients' health status. We did not find any differences in the levels of baseline serum SP-D between non-COPD and incident COPD subjects. This may be because our subjects were healthy without lung injury at baseline, and the level of SP-D may have been within the normal physiological level. If we re-examined the levels of SP-D three years later, there may be some differences between the two groups.

Our study showed that higher baseline serum SP-D may be associated with a slower FEV1 decline in nonCOPD subjects, as a recent large-scale study demonstrated a significant protective relationship between serum SP-D and FEV1 decline (7). In that study, Ma'en Obeidat and coworkers analysed SP-D protein quantitative trait loci (pQTLs) and used Mendelian randomization to demonstrate a causal relationship between serum SP-D levels and COPD risk in 11,157 patients with COPD and 36,699 control subjects. Four SNPs (rs34406153, rs726014, rs144420336, rs12358676) in the SPTPD region, the SNP rs12660817 in the HLA locus and the SNP rs9927461 in the ATP2C2 gene region were found to be associated with SP-D blood levels, SNPs associated with increased serum SP-D levels decreased the risk of COPD, and variants with increased serum SP-D levels had slower declines in lung function. As SP-D plays an important role in controlling chronic inflammation, reducing oxidative radical formation, facilitating phagocytosis and agglutination, reducing cell death and enhancing apoptotic and necrotic cell clearance (4), we speculate that the higher level of SP-D in the physiological state may have a protective effect on the lung. However, because the levels of serum SP-D fluctuate during transient lung injury, it is more reliable to detect the gene polymorphism associated with increased SP-D serum levels rather than serum SP-D. Further large-scale studies in the general population, including SP-D gene polymorphisms, are needed to confirm the causal relationship between SP-D and COPD risk.

This study showed that cigarette smoking and age are significant risk factors for COPD, smoking is the leading cause of accelerated decline in FEV1, and FEV1 in smokers was $32.6 \mathrm{~mL} / \mathrm{y}$ greater than that of nonsmokers, similar to previous studies (14 16). In addition, individuals with incident COPD had a lower baseline FEV1/FEV6 and accelerated decline in FEV1, and the average rate of FEV1 decline in subjects with incident COPD was approximately two-fold greater than that of subjects without COPD, suggesting that lung-function trajectories lead to COPD $(17,18)$. Previous studies have documented that the rate of FEV1 decline varies widely among smokers and patients with COPD $(12,19)$. In the current study, we demonstrated a similar phenomenon. In our study, approximately $50 \%$ of the subjects had a rapid FEV1 decline $(>40 \mathrm{~mL} / \mathrm{y})$, whereas one-third had a slow FEV1 decline and may actually have had improved lung function over time $(<20 \mathrm{~mL} / \mathrm{y})$. Thus, identifying the risk factors for accelerated decline in lung function is important for COPD prevention.

In addition, our study showed traffic exposure and low income may lead to a rapid decline in lung function, while statin use may play a protective role. A previous large-scale cohort study in Taiwan showed that every $5 \mathrm{mug} / \mathrm{m}$ increment in PM2.5 was associated with a $1.18 \%$ decrease in forced vital capacity (FVC) and 1.46\% decrease in FEV1 (20). Low socioeconomic status was associated with increased lung function decline in males, with men in manual social classes in both childhood and adulthood exhibiting the greatest decline in lung function compared with those in non-manual groups in childhood 
and adulthood (21,22). A previous 10-year study in 803 elderly men showed that statin use attenuates the decline in lung function in the elderly population, with the size of the beneficial effect modified by smoking status (23).

The value of the present study includes its prospective nature, longitudinal study design, and first assessment of the predictive value of SP-D for incident COPD in a non-COPD population. The current study also has several limitations. First, the participants in this study were recruited from the community through posters and telephone calls. More women were willing to participate in the study cohort, which may therefore not be representative of the general middle-aged and elderly aged population in China. Second, the dropout rate in our study was relatively high, as some participants moved or refused to continue, leading to a decrease in the strength of our study. The subjects who were lost to follow-up were younger and had higher FEV1/FEV6 ratios than those with followed ups, which may be the reason for the high rate of participants who developed COPD after 3 years of follow-up. Third, SP-D was detected in serum using ELISA, which cannot differentiate between intact (dodecameric) and monomeric or trimeric forms of SP-D.

\section{Conclusions}

In summary, this study shows that there is no association between baseline serum SP-D levels and the development of COPD. Age and smoking status are leading risk factors for COPD. Accelerated FEV1 decline is a core feature of COPD, and serum SP-D levels may be associated with slower FEV1 decline in non-COPD subjects. Traffic exposure and low income may lead to a rapid decline in lung function, whereas statin use may play a protective role against lung function decline. Furthermore, a large-scale cohort prospective study is needed to test the associations between serum SP-D, its associated genetic variations, the development of incident COPD and the decline in lung function in the general population. A predictive model including SP-D levels, a rapid decline in FEV1 and exposure history needs to be established to screen for highrisk groups in communities in China.

\section{Acknowledgments}

We are grateful to Yanni Zhao, Department of Respiratory and Critical Care Medicine, Peking University First Hospital, Beijing, for her contribution to the study design and data collection. She died of colorectal carcinoma in March 2019.

Funding: This work was supported by a grant from the National Key Research and Development Plan (No. 2017YFC1309500), the Capital Medical Development and Scientific Research Fund (No. 2016-1-4071) and the Capital Medical Development and Scientific Research Fund (No. 2007-1004).

\section{Footnote}

Data Sharing Statement: Available at http://dx.doi. org/10.21037/jtd-20-167

Conflicts of Interest: All authors have completed the ICMJE uniform disclosure form (available at http://dx.doi. org/10.21037/jtd-20-1675). The authors have no conflicts of interest to declare.

Ethical Statement: The authors are accountable for all aspects of the work in ensuring that questions related to the accuracy or integrity of any part of the work are appropriately investigated and resolved. The study was conducted in accordance with the Declaration of Helsinki (as revised in 2013). The Ethics Committee of Peking University First Hospital approved the protocol (approval number 2009-168), and written informed consent was obtained from all subjects.

Open Access Statement: This is an Open Access article distributed in accordance with the Creative Commons Attribution-NonCommercial-NoDerivs 4.0 International License (CC BY-NC-ND 4.0), which permits the noncommercial replication and distribution of the article with the strict proviso that no changes or edits are made and the original work is properly cited (including links to both the formal publication through the relevant DOI and the license). See: https://creativecommons.org/licenses/by-nc-nd/4.0/.

\section{References}

1. Lozano R, Naghavi M, Foreman K, et al. Global and regional mortality from 235 causes of death for 20 age groups in 1990 and 2010: a systematic analysis for the Global Burden of Disease Study 2010. Lancet 2012;380:2095-128.

2. Zhong N, Wang C, Yao W, et al. Prevalence of chronic obstructive pulmonary disease in China: a large, 
population-based survey. Am J Respir Crit Care Med 2007;176:753-60.

3. Fang L, Gao P, Bao H, et al. Chronic obstructive pulmonary disease in China: a nationwide prevalence study. Lancet Respir Med 2018;6:421-30.

4. Jakel A, Qaseem AS, Kishore U, et al. Ligands and receptors of lung surfactant proteins SP-A and SP-D. Front Biosci (Landmark Ed) 2013;18:1129-40.

5. Moreno D, Garcia A, Lema D, et al. Surfactant protein D in chornic obstructive pulmonary disease (COPD). Recent Pat Endocr Metab Immune Drug Discov 2014;8:42-7.

6. Lomas DA, Silverman EK, Edwards LD, et al. Serum surfactant protein D is steroid sensitive and associated with exacerbations of COPD. Eur Respir J 2009;34:95-102.

7. Obeidat M, Li X, Burgess S, et al. Surfactant protein D is a causal risk factor for COPD: results of Mendelian randomisation. Eur Respir J 2017;50:1700657.

8. Wang C, Xu J, Yang L, et al. Prevalence and risk factors of chronic obstructive pulmonary disease in China (the China Pulmonary Health $[\mathrm{CPH}]$ study): a national cross-sectional study. Lancet 2018;391:1706-17.

9. Liu S, Zhou Y, Wang X, et al. Biomass fuels are the probable risk factor for chronic obstructive pulmonary disease in rural South China. Thorax 2007;62:889-97.

10. Hu ZW, Zhao YN, Cheng Y, et al. Living near a Major Road in Beijing: Association with Lower Lung Function, Airway Acidification, and Chronic Cough. Chin Med J (Engl) 2016;129:2184-90.

11. Jing JY, Huang TC, Cui W, et al. Should FEV1/FEV6 replace FEV1/FVC ratio to detect airway obstruction? A metaanalysis. Chest 2009;135:991-8.

12. Petersen H, Sood A, Meek PM, et al. Rapid lung function decline in smokers is a risk factor for COPD and is attenuated by angiotensin-converting enzyme inhibitor use. Chest 2014;145:695-703.

13. Sin DD, Man SF, Marciniuk DD, et al. The effects of fluticasone with or without salmeterol on systemic biomarkers of inflammation in chronic obstructive pulmonary disease. Am J Respir Crit Care Med

Cite this article as: Liao JP, Wang X, Liu F, Cheng Y, Hu ZW, Zhang LN, Xia GG, Zhang C, Ma J, Wang GF. Serum surfactant protein $\mathrm{D}$, lung function decline, and incident chronic obstructive pulmonary disease: a longitudinal study in Beijing. J Thorac Dis 2021;13(1):92-100. doi: 10.21037/jtd-201675
2008; 177:1207-14.

14. Rennard SI, Vestbo J. COPD: the dangerous underestimate of 15\%. Lancet 2006;367:1216-9.

15. Pérez-Padilla R, Fernandez-Plata R, Montes de Oca M, et al. Lung function decline in subjects with and without COPD in a population-based cohort in Latin-America. PLoS One 2017;12:e177032.

16. Mirabelli MC, Preisser JS, Loehr LR, et al. Lung function decline over 25 years of follow-up among black and white adults in the ARIC study cohort. Respir Med 2016;113:57-64.

17. Pauwels RA, Löfdahl CG, Laitinen LA, et al. Longterm treatment with inhaled budesonide in persons with mild chronic obstructive pulmonary disease who continue smoking. European Respiratory Society Study on Chronic Obstructive Pulmonary Disease. N Engl J Med 1999;340:1948-53.

18. Lange P, Celli B, Agustí A, et al. Lung-Function Trajectories Leading to Chronic Obstructive Pulmonary Disease. N Engl J Med 2015;373:111-22.

19. Vestbo J, Edwards LD, Scanlon PD, et al. Changes in forced expiratory volume in 1 second over time in COPD. N Engl J Med 2011;365:1184-92.

20. Guo C, Zhang Z, Lau AKH, et al. Effect of long-term exposure to fine particulate matter on lung function decline and risk of chronic obstructive pulmonary disease in Taiwan: a longitudinal, cohort study. Lancet Planet Health 2018;2:e114-25.

21. Ramsay SE, Whincup PH, Lennon LT, et al. Longitudinal associations of socioeconomic position in childhood and adulthood with decline in lung function over 20 years: results from a population-based cohort of British men. Thorax 2011;66:1058-64.

22. Johannessen A, Eagan TM, Omenaas ER, et al. Socioeconomic risk factors for lung function decline in a general population. Eur Respir J 2010;36:480-7.

23. Alexeeff SE, Litonjua AA, Sparrow D, et al. Statin use reduces decline in lung function: VA Normative Aging Study. Am J Respir Crit Care Med 2007;176:742-7. 